\title{
Synchronous Detection of Hairy Cell Leukemia and HIV-Negative Kaposi's Sarcoma of the Lymph Node: A Diagnostic Challenge and a Rare Coincidence
}

\author{
Seniz Ongoren Aydin ${ }^{\mathrm{a}} \quad$ Ahmet Emre Eskazan $^{\mathrm{a}}$ Hilal Aki \\ Mustafa Ozguroglu ${ }^{b}$ Zafer Baslar ${ }^{a}$ Teoman Soysal ${ }^{a}$ \\ Divisions of a Hematology and ${ }^{\mathrm{b} M e d i c a l}$ Oncology, Department of Internal \\ Medicine, and 'Department of Pathology, Istanbul University Cerrahpasa Faculty \\ of Medicine, Istanbul, Turkey
}

\section{Key Words}

Hairy cell leukemia $\cdot$ Kaposi's sarcoma $\cdot$ Simultaneous diagnosis

\begin{abstract}
Hairy cell leukemia $(\mathrm{HCL})$ is an uncommon chronic lymphoproliferative disorder and accounts for around $2 \%$ of all forms of leukemias. The association of $\mathrm{HCL}$ with other neoplasms, mainly non-Hodgkin's lymphomas, is well known. However, the simultaneous diagnosis of HCL and Kaposi's sarcoma is rare, with only few cases of such an association having been reported. We describe a 42-year-old male patient with a well characterized $\mathrm{HCL}$ and in whom HIV-negative Kaposi's sarcoma of the lymph node was detected.
\end{abstract}

\section{Introduction}

Hairy cell leukemia (HCL) is an uncommon chronic lymphoproliferative disorder and accounts for around $2 \%$ of all forms of leukemias [1]. The disease is characterized by a variable degree of splenomegaly, pancytopenia, and infiltration of the bone marrow with lymphocytes that have irregular cytoplasmic projections when identified in the peripheral blood. Kaposi's sarcoma (KS) is a tumor caused by human herpesvirus-8 (HHV-8), also known as KS-associated herpesvirus. It is a systemic disease which can present with cutaneous lesions with or without visceral involvement. The cutaneous lesions can be solitary, localized or disseminated. KS can involve the oral cavity, lymph nodes, and viscera. KS can be seen in iatrogenically immunosuppressed patients and was 
documented in association with lymphoproliferative disorders including HCL. Here we report a patient synchronously who was diagnosed with both HCL and HIV-negative KS of the lymph node and who died of bacterial meningitis.

\section{Case Report}

A 42-year-old man was referred to the medical oncology department with bilateral palpable inguinal lymphadenopathies persisting for 1 month. His medical history was unremarkable and he did not have any constitutional symptoms. He was fit and the physical examination revealed pallor, palpable splenomegaly at $3 \mathrm{~cm}$ below the left costal margin and bilateral posterior cervical and inguinal lymphadenopathies of $1 \mathrm{~cm}$ in diameter. He had neither skin nor mucosal lesions. Laboratory investigations revealed a hemoglobin of $6.7 \mathrm{~g} / \mathrm{l}$ (Hct: 20.3\%, MCV: $93.7 \mathrm{fl}$, Rtc: $2.3 \%)$, white-blood cell count of $2.6 \times 10^{9} / \mathrm{l}$ (neutrophils $0.1 \times 10^{9} / \mathrm{l}$, lymphocytes $2.0 \times 10^{9} / \mathrm{l}$, monocytes $0.05 \times 10^{9} / \mathrm{l}$ ), and a platelet count of $37 \times 10^{9} / \mathrm{l}$, erythrocyte sedimentation rate $(\mathrm{ESH}): 110 \mathrm{~mm} / \mathrm{h}, \mathrm{LDH}: 169 \mathrm{U} / \mathrm{l}$, beta-2 microglobulin: 2,931 ng/ml, haptoglobin: $153 \mathrm{mg} / \mathrm{dl}$, direct antiglobulin (Coombs) test: positive, and indirect Coombs test: negative. The IgA and IgG levels were within the normal ranges (IgA: $188 \mathrm{mg} / \mathrm{dl}$, IgG: $1,470 \mathrm{mg} / \mathrm{dl})$, but IgM was slightly decreased $(31.8 \mathrm{mg} / \mathrm{dl})$. The thoracic computed tomography (CT) showed lymphadenopathies with diameters of $1.5 \mathrm{~cm}$ in the bilateral axillary, supraclavicular, mediastinal and retrocrural regions. There were lymphadenopathies of $2 \mathrm{~cm}$ in diameter in the retrocrural, paraaortic, peripancreatic and inguinal regions and splenomegaly in abdomen CT.

In the histopathological examination of the excisional lymph node biopsy from the left inguinal lymph node, the normal structure of the lymph node did not exist and it was infiltrated with a tumor in diffuse and nodular pattern. The tumor cells had spindle-shaped nuclei with fasciculi formation (fig. 1.a), and the immunohistochemistry of the tumor cells showed CD31 positivity and they were CD20, CD23, S-100, CD68 and CD45RO negative. The dendritic cells were positive for CD23I in the lymph follicles other than the tumor-invaded areas. With all these findings the diagnosis was KS. The patient was negative for human immunodeficiency virus (HIV), and HHV-8 positivity was detected by nested polymerase chain reaction (PCR) from the blood. The lymph node biopsy specimen which was consistent with KS showed positive immunostaining with anti-HHV-8 antibody (fig. 1b).

Peripheral blood film showed normochromic red cells, absolute monocytopenia, atypical lymphoid cells with surface projections - 'hairy cells' and thrombocytopenia (ig. 2). Flow cytometry from the peripheral blood was done and the atypical lymphocytes showed strong expression of CD11c, CD103, CD25, CD20, CD22, and CD19. The cells were negative for CD5, CD23, CD34, CD10, and myeloid markers. A diagnosis of HCL was made. The bone marrow biopsy revealed an interstitial and diffuse infiltrate of atypical cells with widely spaced, small, round or bean-shaped nuclei, abundant cytoplasm and prominent cell borders that produced the classical 'fried egg' appearance (fig. 3a). The atypical cells were CD20 positive (fig. 3b), and an increase in reticulin fibers was also seen (fig. 3c), and tartrateresistant acid phosphatase (TRAP) was found to be positive in the bone marrow (fig. $3 \mathrm{~d}$ ). The bone marrow biopsy was negative for anti-HHV-8 antibody immunostaining.

A very short time period after the diagnostic process, before any specific treatment was initiated, the patient's disease was complicated by bacterial meningitis and he died.

\section{Discussion}

HCL is an uncommon chronic lymphoproliferative disorder. Splenomegaly is common, sometimes may be massive and is found in approximately $90 \%$ of the patients with HCL [2]. Unlike many other lymphoproliferative disorders, peripheral lymphadenopathy is uncommon in HCL, with less than $10 \%$ of patients presenting with peripheral nodes larger than $2 \mathrm{~cm}$ in diameter. Although adenopathy is not common at diagnosis, internal lymphadenopathy(ies) may develop after a prolonged disease course and is present in $75 \%$ of patients at autopsy [3-5]. Our patient was admitted to the medical oncology department with peripheral inguinal lymphadenopathy, and he had 
internal lymphadenopathies as well, so a lymph node biopsy was performed since lymphoproliferative disorder was thought to be the case. But the lymph node biopsy revealed KS. KS may be associated with pancytopenia due to HHV-8 viremia, bone marrow infiltration or hemophagocytosis [6,7]. Our patient had pancytopenia but did not have bone marrow infiltration of KS or hemophagocytosis in the bone marrow. The peripheral blood and bone marrow studies showed HCL as an additional malignancy.

If this patient was admitted to a hematology department first, the focus could be on the pancytopenia and HCL might be the initial diagnosis, and the lymphadenopathies would be attributed to the lymphoproliferative disorder so a lymph node biopsy would not be done. Since the diagnosis of KS came with the lymph node biopsy, a lymph node biopsy should be kept in mind in patients with HCL who have peripheral lymphadenopathy(ies).

The patient was HIV negative and positive for HHV-8 (both serologically and by antiHHV-8 antibody immunostaining within the lymph node), which is shown to be responsible in the pathogenesis of KS [8].

An association has been noticed between HCL and other malignancies, although the link is controversial. A number of studies have demonstrated an increased incidence of secondary tumors in HCL, including melanoma, prostate cancer, gastrointestinal cancers, non-Hodgkin's lymphoma, and non-melanomatous skin cancers $[9,10]$. It is not clear whether HCL itself increases the risk or whether the therapy plays a role. Our patient had HCL and KS synchronously, so he did not receive any therapy that may play a role in the development of a second malignancy. Although there are reports indicating the association between HCL and KS [11, 12], to our knowledge, this is the first case presented in the English literature who developed HCL and KS synchronously.

Although diagnosed synchronously, our patient most probably had HCL for a longer period of time, and it could be speculated that the cause of the KS in this case was the immunosuppressive state due to HCL.

KS may involve lymph nodes [13], and the coexistence of KS with the other lymphoproliferative disorders such as chronic lymphocytic leukemia, Hodgkin's lymphoma, and Castleman's disease in the same lymph node had been published before [14-16]. In the present case the lymph node biopsy did not show any findings for HCL.

Autoimmune hemolytic anemia (AIHA) have been previously described in association with KS [17]. Our patient had a positive DAT but no signs of AIHA. Patients with KS acquire numerous opportunistic infections including cytomegalovirus and Pneumocystis jirovecii [18]. HCL is also associated with an increased incidence of serious infections. The factors predisposing to infection in HCL include neutropenia, monocytopenia, administration of corticosteroids, splenectomy and possibly defective cell-mediated immune responsiveness [19-21]. Patients with KS and HCL, regardless of the underlying or associated disease process, may be at increased risk for developing opportunistic infections and should be monitored for these complications [12]. This case had neutropenia and monocytopenia, did not have splenectomy or receive steroids and his disease was complicated by bacterial meningitis and he died before any specific treatment against the malignancies could be administered. 

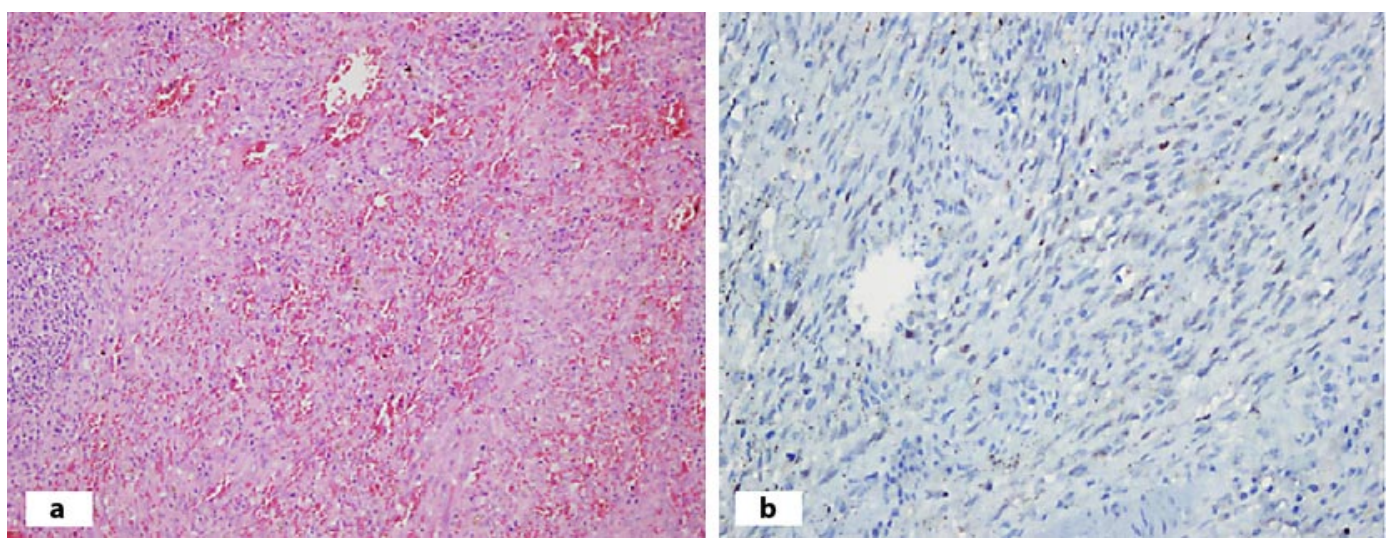

Fig. 1. Elongated spindle cells are separated by slits containing red blood cells in lymph node with Kaposi's sarcoma (hematoxylin and eosin stain, $\times 200$ ) (a), anti-HHV-8 antibody immunostaining positivity detected in the lymph node $(\times 400)(\mathbf{b})$.

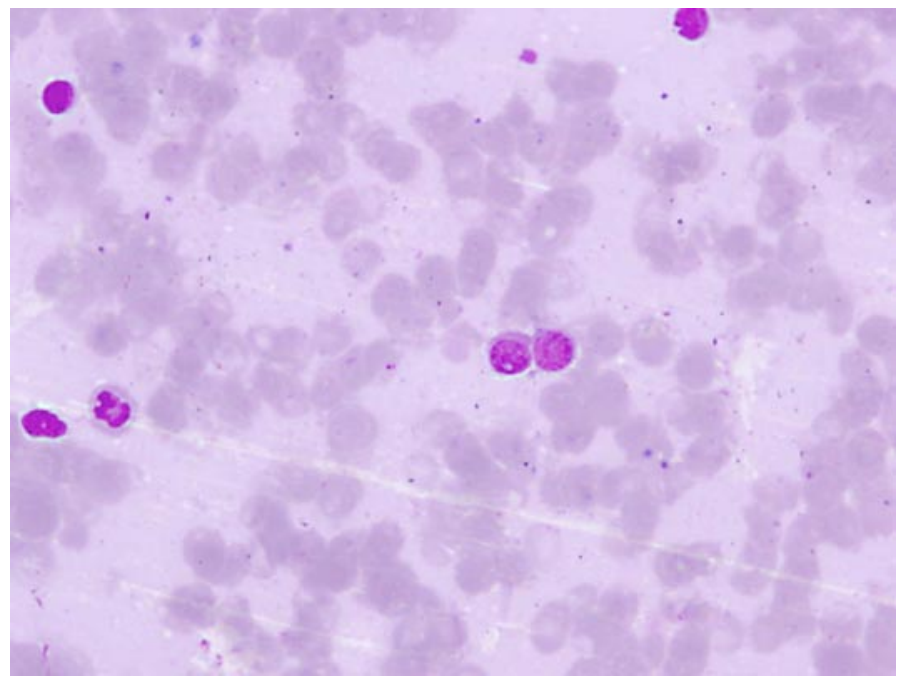

Fig. 2. Peripheral blood film showing atypical lymphoid cells with surface projections - 'hairy cells' (Giemsa stain, $\times 1,000$ ). 

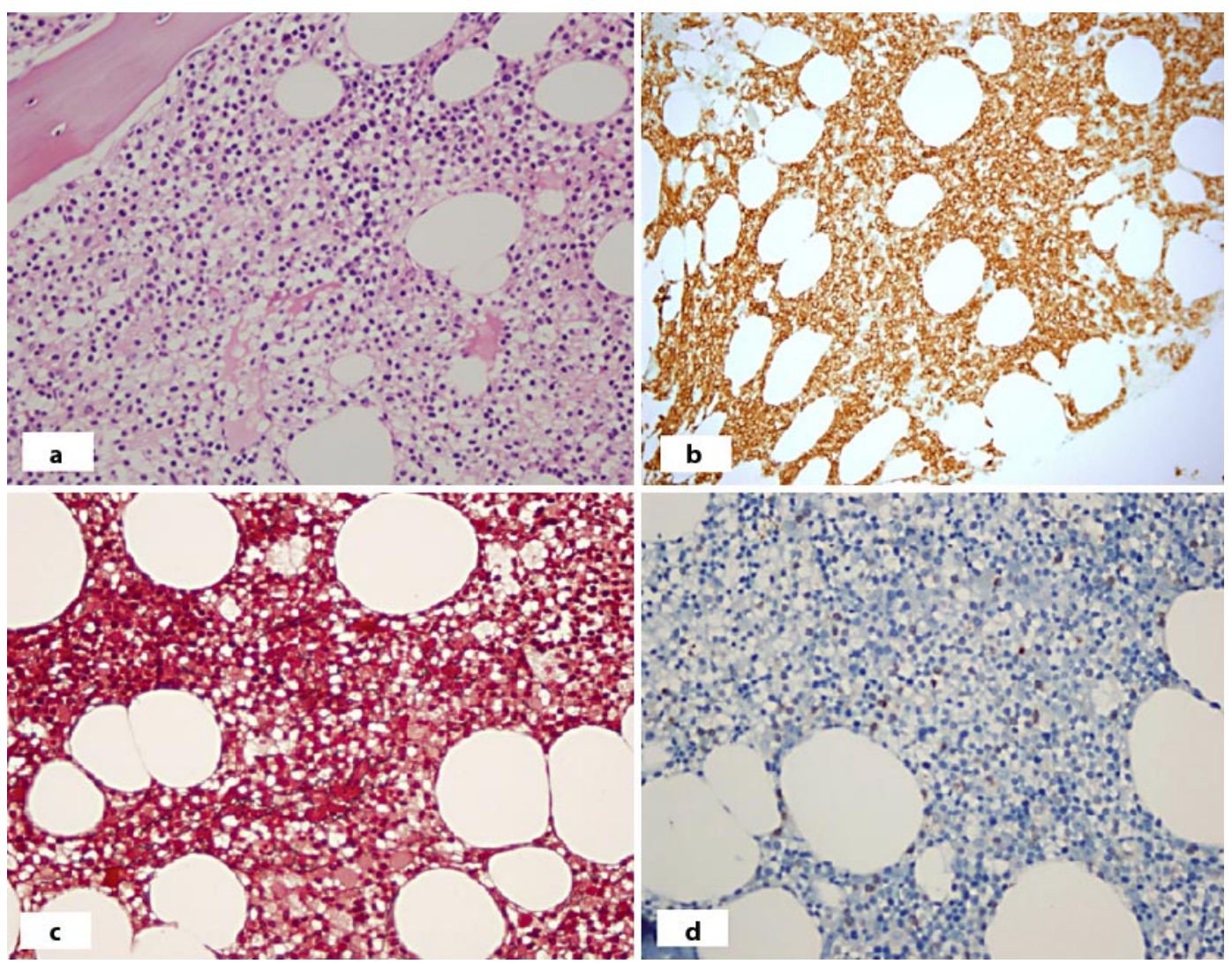

Fig. 3. The bone marrow is markedly hypercellular due to interstitial and diffuse infiltration of hairy cells (hematoxylin and eosin stain, $\times 400)(\mathbf{a})$, the hairy cells are intensely reactive with CD20 $(\times 200)(\mathbf{b})$. Reticulin stain of the bone marrow biopsy shows a moderate increase in reticulin fibers, and the reticulin fibers appear to individually circumscribe the hairy cells $(\times 400)(\mathbf{c})$. Tartrate-resistant acid phosphatase (TRAP) positivity was detected in the bone marrow $(\times 400)(\mathbf{d})$.

\section{References}

1 Grey MR, Flanagan NG, Kelsay PR: Severe skin rash in two consecutive patients treated with 2chlorodeoxydenosine for hairy-cell leukaemia at a single institution. Clin Lab Haematol 2000;22:111-113.

2 Golomb HM: Hairy cell leukemia: an unusual lymphoproliferative disease: a study of 24 patients. Cancer 1978;42(2 suppl):946-956.

-3 Vardiman YW, Golomb HM: Autopsy findings in hairy cell leukemia. Semin Oncol 1984;11:370-380.

4 Mercieca J, Puga M, Matutes E, et al: Incidence and significance of abdominal lymphadenopathy in hairy cell leukemia. Leuk Lymphoma 1994;14(suppl 1):79-83.

5 Hakimian D, Tallman MS, Hogan DK, et al: Prospective evaluation of internal adenopathy in a cohort of 43 patients with hairy cell leukemia. J Clin Oncol 1994;12:268-272.

6 Luppi M, Barozzi P, Rasini V, et al: Severe pancytopenia and hemophagocytosis after HHV-8 primary infection in a renal transplant patient successfully treated with foscarnet. Transplantation 2002;74:131-132.

7 Pich A, Navone R: Bone marrow involvement in Kaposi's disease. Report of a case. Panminerva Med 1989;31:144-147.

8 Mesri EA, Cesarman E, Boshoff C: Kaposi's sarcoma and its associated herpesvirus. Nat Rev Cancer 2010;10:707-719.

9 Dasanu CA, Alexandrescu DT: Risk of additional cancers in untreated and treated hairy cell leukemia patients. Expert Opin Pharmacother 2010;11:41-50. 
10 Hisada M, Chen BE, Jaffe ES, Travis LB: Second cancer incidence and cause-specific mortality among 3,104 patients with hairy cell leukemia: a population-based study. J Natl Cancer Inst 2007;99:215-222.

11 De Cock KM, Kasili EG, Lucas SB, et al: Kaposi’s sarcoma associated with hairy cell leukaemia. Postgrad Med J 1983;59:258-259.

12 Hocking W, Lazar G, Goldsmith M, et al: Kaposi's sarcoma associated with hairy cell leukemia, immune thrombocytopenia, and opportunistic infection. Cancer 1984;54:110-113.

13 Ramos CV, Taylor HB, Hernandez BA, et al: Primary Kaposi's sarcoma of lymph nodes. Am J Clin Pathol 1976;66:998-1003.

14 Koren G, Okon E, Zlotnick A: Coexistence of Kaposi's sarcoma and chronic lymphocytic leukemia in the same lymph node. Cancer 1984;54:110-113.

15 Massarelli G, Tanda F, Denti S: Primary Kaposi's sarcoma and Hodgkin's disease in the same lymph node. Am J Clin Pathol 1982;78:107-111.

16 Rywlin AM, Rosen L, Cabello B: Coexistence of Castleman's disease and Kaposi's sarcoma. Report of a case and a speculation. Am J Dermatopathol 1983;5:277-281.

17 Schreiker ZA, Haim S, Gellei B, Tatarsky I: Autoimmune hemolytic anemia in the course of Kaposi's sarcoma: Report of case. Cancer 1973;32:922-925.

18 Gottlieb MS, Schroff R, Schanker HM, et al: Pneumocystis carinii pneumonia and mucosal candidiasis in previously healthy homosexual men: evidence of a new acquired cellular immunodeficiency. N Eng J Med 1981;305:1425-1431.

19 Bouza E, Burgaleta C, Golde DW: Infections in hairy cell leukemia. Blood 1978;51:851-859.

20 Steware DJ, Bodey GP: Infections in hairy cell leukemia (leukemic reticuloendotheliosis). Cancer 1981;47:801805.

21 Mackowiak PA, Demian SE, Sutker WL: Infections in hairy cell leukemia: clinical evidence of a pronounced defect in cell mediated immunity. Am J Med 1980;68:718-724. 